\title{
Numerical simulation of the current, potential and concentration distributions along the cathode of a rotating cylinder Hull cell
}

\author{
C.T.J. Low ${ }^{\text {a }}$, E.P.L. Roberts ${ }^{b}$, F.C. Walsh ${ }^{\mathrm{a}, *}$ \\ ${ }^{a}$ Electrochemical Engineering Group, School of Engineering Sciences, University of Southampton, \\ Highfield, Southampton SO17 1BJ, United Kingdom \\ ${ }^{\mathrm{b}}$ School of Chemical Engineering and Analytical Science, University of Manchester, \\ P.O. Box 88, Sackville Street, Manchester M60 1QD, United Kingdom
}

Received 28 August 2006; received in revised form 27 October 2006; accepted 28 October 2006

Available online 28 November 2006

\begin{abstract}
Numerical simulations of the non-uniform current, potential and concentration distributions along the cathode of a rotating cylinder Hull (RCH) cell (RotaHull ${ }^{\circledR}$ cell) are performed using finite element methods. Copper electrodeposition from an acid sulfate electrolyte is used as a test system. Primary, secondary and tertiary current distributions are examined. The importance of controllable and uniformly accessible hydrodynamics along the length of the $\mathrm{RCH}$ cathode is demonstrated. Charge transfer kinetics are described by a Tafel approximation while mass transport is considered using a Nernstian diffusion layer expression. The effects of applied current density and electrode rotation speeds on the distribution of potential and current along the RCH cathode are investigated. An expression of the primary current distribution and a dimensionless mass transport correlation facilitate comparisons with the simulations.
\end{abstract}

(C) 2006 Elsevier Ltd. All rights reserved.

Keywords: Copper electrodeposition; Nernst diffusion layer; Finite element method; Current, potential and concentration distributions; Mass transport; Hydrodynamics; Modelling; Rotating cylinder electrode (RCE); Rotating cylinder Hull (RCH) cell

\section{Introduction}

The Hull cell, a trapezoidal test cell for electroplating, was first introduced in 1939 [1] and has been used as an experimental tool for the investigations of single metal, alloy and composite deposition. It consists of an anode, inclined cathode and two insulating walls. The design enables a wide range of current densities to be achieved in a single experiment. Although the classical Hull cell has been used for many years, particularly in electroplating process control laboratories, it has many experimental limitations. These may include poorly defined hydrodynamic conditions where the trapezoidal dimension may introduce non-uniform stirring of electrolyte and local variations of temperature, $\mathrm{pH}$, conductivity and composition can occur. These shortcomings have restricted the use of the Hull cell for controllable and reproducible mass transport conditions.

\footnotetext{
* Corresponding author.

E-mail address: F.C.Walsh@ soton.ac.uk (F.C. Walsh).
}

In order to achieve controllable hydrodynamic conditions, many design modifications of the Hull cell have been explored. These include an early study of high-speed electrodeposition by Graham and Pinkerton [2]. Their design consisted of a conical counter electrode placed symmetrically around the rotating cylinder electrode. Many modern variants of the rotating cylinder Hull $(\mathrm{RCH})$ cell are available and have provided an important experimental tool for electrodeposition studies. Such geometries have been used for the measurement of non-uniform current distribution, mass transport and throwing power of plating baths at controlled turbulent flow condition $[3,4]$.

For quantitative and high-speed electrodeposition studies, Afshar et al. have provided experimental measurements of copper deposition in four variants of the rotating Hull cell [5]. The design utilised upright or inverted conical cathodes and a cylindrical outer anode, an RCE cathode with a segmented inclined cathode and a rotating cylinder electrode (RCE) cathode with the anode set at $52^{\circ}$ and below the RCE. Another example include Kadija et al. have studied an RCE cathode with a co-rotating anode on the lower part of the shaft (in the absence 
and presence of conical or disc insulated baffles). Palladium and nickel deposition were considered but no simulations of the current distribution were provided [6].

Madore and Landolt introduced an RCE nickel cathode $\left(d=1 \mathrm{~cm}, l=6 \mathrm{~cm}, A=28.3 \mathrm{~cm}^{2}\right)$ with an asymmetrically placed copper anode and a concentric insulating separator [7]. The primary and secondary current distribution for deposition of copper-nickel alloys from a citrate electrolyte was studied. The cell utilised an insulating, cylindrical separator and a lower disc anode at $90^{\circ}$ to the axis of rotation. Copper deposition from an acidic sulfate solution was used to compare the distribution of experimental deposits thickness with values predicted by a secondary current distribution model [8].

They have also studied an RCH cell for copper deposition from sulfate or pyrophosphate solution [9]. The distribution of current density was compared with a primary current distribution model and the throwing power of the solutions was considered. The boundary element method was used in these simulations [10]. A recent investigation by Mandin et al. has considered the modelling of the natural/forced convection regime around a rotating cylinder electrode using a computational flow dynamics approach [11].

A recent, commercially developed RCH cell, the RotaHull ${ }^{\circledR}$ cell [12] consists of a rotating cylinder working electrode, a stationary concentric insulator cylinder and a concentric counter electrode (Fig. 1). This cell enables the investigation of a wide range of current density in a single experiment, under wellcontrolled mass transport conditions. This is most beneficial for quantitative electrodeposition studies as it allows reproducible quality of deposits and monitoring of electrolyte under controlled operating conditions. The dimensions have been chosen to give a primary current distribution similar to the classical trapezoidal Hull cell. An empirical equation for the primary current distribution on a similar $\mathrm{RCH}$ cell has been reported in the literature $[9,10]$ :

$$
\begin{aligned}
\frac{j_{x}}{j_{\text {ave }}}= & \frac{0.535-0.458 \times(x / h)}{\left[0.0233+(x / h)^{2}\right]^{0.5}}+8.52 \times 10^{-5} \\
& \times \exp \left[7.17 \times\left(\frac{x}{h}\right)\right]
\end{aligned}
$$

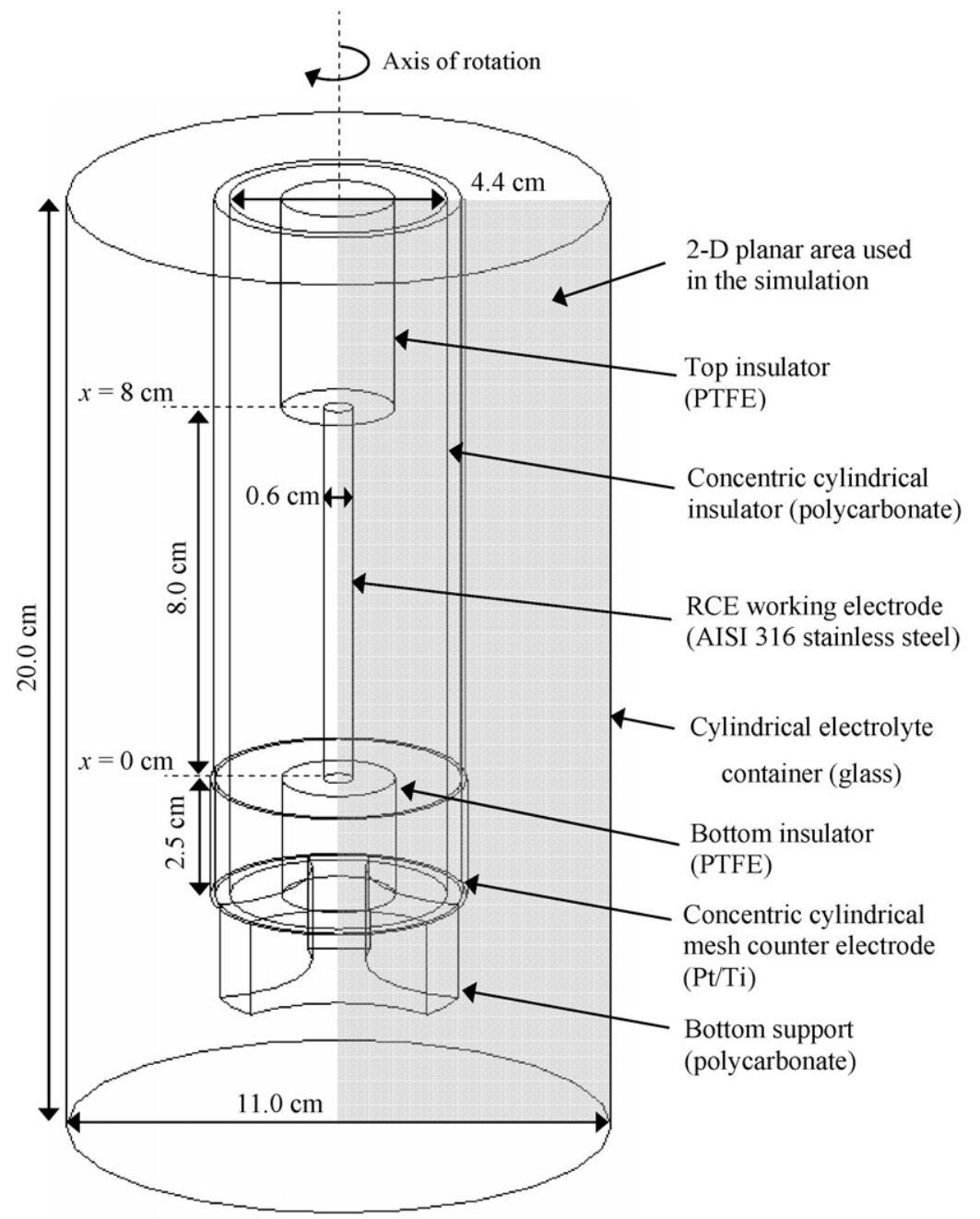

Fig. 1. The rotating cylinder Hull $(\mathrm{RCH})$ cell, RotaHull $\mathrm{P}^{\circledR}[12]$. The working electrode is a rotating cylindrical electrode $(316 \mathrm{stainless}$ steel, $0.6 \mathrm{~cm}$ diameter, $8.0 \mathrm{~cm}$ length); the counter electrode is a concentric cylindrical electrode ( $\mathrm{Pt} / \mathrm{Ti}, 0.1 \mathrm{~cm}$ thickness, $5.2 \mathrm{~cm}$ inside diameter, $2.5 \mathrm{~cm}$ height). The highlighted $2 \mathrm{D}$ planar area is the computational domain used in the numerical simulation. 
where $j_{\text {ave }}$ is the average (applied) current density on the working electrode, $j_{x}$ the local current density on the working electrode and $x / h$ is the dimensionless distance along the working electrode.

In summary, modelling of RCH cells has been focussed on both the primary and secondary current distribution with very few studies of the tertiary current distribution. In this work, the primary, secondary and tertiary current distributions in an RCE (with an offset anode) are calculated using standard finite element software (FEMLAB ${ }^{\mathrm{TM}}$ ). The simulations have been carried out under conditions of forced convection. The turbulent flow was controlled by the rotation speed of an RCE. The geometry of the RCH cell determines the primary current distribution, the secondary current distribution is used to describe the effects of charge transfer and the tertiary current distribution is used to describe the combined effects of charge transfer and mass transport.

\section{Description of the rotating cylinder Hull cell}

Fig. 1 shows the geometry of the RotaHull ${ }^{\circledR}$ cell [12]. It consists of a rotating cylinder working electrode (316 stainless steel, $8.0 \mathrm{~cm}$ height, $0.6 \mathrm{~cm}$ diameter), a stationary concentric counter electrode (Pt/Ti, $0.1 \mathrm{~cm}$ thickness, $2.5 \mathrm{~cm}$ height, $5.2 \mathrm{~cm}$ inside diameter), top and bottom PTFE cylindrical insulator $(2.3 \mathrm{~cm}$ diameter, $4.5 \mathrm{~cm}$ or $2.5 \mathrm{~cm}$ length, respectively), a concentric polycarbonate insulator $(4.4 \mathrm{~cm}$ inner diameter, $5.0 \mathrm{~cm}$ outside diameter, $15.0 \mathrm{~cm}$ length), a stationary bottom polycarbonate support, and a cylindrical glass electrolyte container $(11.0 \mathrm{~cm}$ inside diameter, $20.0 \mathrm{~cm}$ height). The working electrode was positioned centrally; the top and bottom insulator protruded by $0.85 \mathrm{~cm}$ from the working electrode and formed a $90^{\circ}$ angle with it. The counter electrode was placed outside the concentric polycarbonate insulator and the current and potential distributions in the electrolyte were provided via an opening in the bottom of the concentric polycarbonate insulator. The distance from the circumferential face of the bottom PTFE insulator to the inner face of the concentric polycarbonate insulator was $1.05 \mathrm{~cm}$.

With this $\mathrm{RCH}$ cell design, a deliberately non-uniform current-potential-concentration distribution will occur along the length of the working electrode. This is due to the varying distance between the working and counter electrode. The position at $x=0$ has the highest current density and electrode potential because it is nearest to the counter electrode. At $x=8$, the lowest current density and electrode potential arises furthest from the counter electrode. The bottom polycarbonate support has only a minor shielding effect of the current and potential distribution along the cathode. The current and potential distributions in the radial direction along the working electrode are uniformly distributed. The deposited metal was assumed to have a uniform thickness circumferentially, being time-averaged by the rotation of the cathode.

\section{Formulation of numerical simulation}

Simulations of the primary, secondary and tertiary current distributions were carried out. The shaded planar area in Fig. 1 was used as the domain for the numerical simulations. In primary current distribution, the non-uniform current distribution profile was influenced by the geometry of the RCH cell. In secondary and tertiary current distributions cases, the Tafel approximation was used for the electrochemical kinetics. For the tertiary current distribution, a Nernst diffusion layer model was used with the boundary layer thickness estimated from a literature mass transport correlation $[13,14]$. Under the turbulent flow conditions considered, the Nernst diffusion layer thickness can be assumed to be uniform $[17,18]$ but the local rates of reaction (overpotential, current density and concentration) were assumed to be distributed non-uniformly along the length of the working electrode. Two electrolyte subdomains were defined: diffusion layer region and free electrolyte region. It was assumed that the potential drop of the metal resistivity along the cathode was negligible.

The current density, $j$ at any point inside the $\mathrm{RCH}$ cell was determined from the gradient of local potential, $\phi$ according to Ohm's Law [2]:

$j=-\kappa \nabla \phi$

where $\kappa$ is the electrolyte conductivity. The potential distribution in the electrolyte was described by the Laplace equation:

$\nabla^{2} \phi=0$

Depending on the characteristics of the boundary conditions on the cathode, three types of current distribution models can be specified. For a primary current distribution, the surface potential of the working electrode was set equal to the potential of the solution adjacent to the electrode, $\phi_{0}$ :

$V=\phi_{0}$

The primary current distribution assumed both the charge transfer and mass transport conditions are negligible. In this case, the main aspect that determines the current distribution is the ohmic resistance within the $\mathrm{RCH}$ cell. The electrochemical reaction on the working electrode was considered reversible and the primary current distribution is dependent solely on the geometry of the $\mathrm{RCH}$ cell.

A secondary current distribution can be obtained when the electrochemical reaction is dependent on the charge transfer only and the concentration gradient is negligible. The concentration of copper ions is assumed similar at the cathode surface and bulk electrolyte. Under these conditions, the local current density can be related to the local overpotential, $\eta$ on the electrode. The overpotential is the potential difference between the electrode and the solution adjacent to the electrode:

$\eta=V-\phi_{0}$

The overpotential is adequately related to the magnitude of the local current density through the Tafel approximation:

$j=-j_{\mathrm{o}} \exp \left(-\frac{\eta}{b_{\mathrm{c}}}\right)$

where $b_{\mathrm{c}}$ is the Tafel slope, and $\eta$ is the overpotential at the electrode. For the secondary current distribution model, the boundary conditions are expressed as follows. 
No current flows at all insulating surfaces, where $\xi$ is the normal direction to the boundary:

$-\kappa \frac{\partial \phi}{\partial \xi}=0$

If Tafel kinetics are applied at the working electrode under charge transfer controlled conditions:

$-\kappa \frac{\partial \phi}{\partial \xi}=-j_{\mathrm{o}} \exp \left(-\frac{\eta}{b_{\mathrm{c}}}\right)$

The counter electrode is assumed reversible with a constant applied current density:

$-\kappa \frac{\partial \phi}{\partial \xi}=j_{\text {ave }}\left(\frac{A_{\mathrm{WE}}}{A_{\mathrm{CE}}}\right)$

where $j_{\text {ave }}$ is the average current density on the working electrode, and $A_{\mathrm{WE}}$ and $A_{\mathrm{CE}}$ are the area of working and counter electrode, respectively. In practice, the average current density is the applied current density between the working and counter electrode. Although the current distribution at the counter electrode will be non-uniform in real situation, this was found to have a negligible effect on the working electrode.

Simulations using a fixed anode potential showed that (for the same current) the cathodic current distribution was negligibly affected. This approach allowed the average current density to be fixed. Trial simulations on a uniform current distribution model indicated that the area ratio in Eq. (9) was necessary in order to solve the simulation adequately without any loss of generality. Using this modified boundary condition for the counter electrode, the current density at the working electrode could be directly controlled. Based on the conservation of charge, the numerically simulated average current on the working electrode should be equal to the total current on the counter electrode.

When the concentration gradient is significant, the electrochemical reaction is dependent on both the charge transfer and mass transport. For these conditions, a tertiary current distribution was obtained using a Nernst diffusion layer model $[15,16]$. The concentration was assumed to vary only inside a stagnant layer next close to the cathode surface. Inside this layer, the convection along the $\mathrm{RCH}$ cathode was negligible and diffusion dominated the mass transport phenomenon. Outside this layer the concentration was assumed to be constant and equal to the bulk concentration, $c_{\mathrm{b}}$. The concentration distribution within the boundary layer followed the Laplace equation:

$\nabla^{2} c=0$

The thickness of the diffusion layer, $\delta_{\mathrm{N}}$ varied with the electrode rotation speed, i.e. the strength of the turbulent flow inside the RCH cell. The thickness was estimated from a mass transport dimensionless equation predicted by Eisenberg et al. [17,18]. This correlation is valid for hydrodynamically smooth rotating cylinder electrodes in turbulent flow:

$\delta_{\mathrm{N}}=12.64 U^{-0.7} d^{0.3} v^{0.34} D^{0.356}$

where $U$ is the peripheral velocity of the working electrode, $d$ the diameter of the rotating cylinder electrode, $v$ the kine- matic viscosity and $D$ is the diffusion coefficient of copper ions. The diffusion layer thickness along the cathode of the RCH cell remained constant. The boundary conditions for tertiary current distribution calculations are defined as follows.

At insulating surfaces, no current flows and there are no concentration changes:

$-\kappa \frac{\partial \phi}{\partial \xi}=0 ; \quad D \frac{\partial c}{\partial \xi}=0$

If a modified Tafel kinetics (concentration factor is included) is applied at the working electrode:

$-\kappa \frac{\partial \phi}{\partial \xi}=-j_{\mathrm{o}}\left(\frac{c}{c_{\mathrm{b}}}\right) \exp \left(-\frac{\eta}{\beta_{\mathrm{c}}}\right)$

The flux of copper ions at the working electrode can be determined from Faraday's law of electrolysis:

$D \frac{\partial c}{\partial \xi}=\frac{j_{\mathrm{o}}\left(c / c_{\mathrm{b}}\right) \exp \left(-\eta / \beta_{\mathrm{c}}\right)}{z F}$

The concentration of the outer boundary layer is equal to the bulk concentration:

$c=c_{\mathrm{b}}$

The current density is assumed to be uniform at the counter electrode, according to Eq. (9).

Eqs. (10)-(15) were solved using the finite element simulation package, FEMLAB ${ }^{\mathrm{TM}}$. The space dimension is based on the 'Axial symmetry 2D' formulations. A 'Stationary Nonlinear' with the 'Direct UMFPACK' solver system was used. A multiphysics formulation was used in the modelling. The subdomains and boundaries were created by the 'Diffusion' and 'Electromagnetic' functions. The enclosed domains are within the boundaries of the insulator walls, the working and counter electrode. This was decomposed into a finite number of triangular elements for the simulations, as shown in Fig. 2.

The solution time was dependent on the number of mesh elements. For example, for 10,000-25,000 mesh elements, 60-140 s was required. For 140,000-300,000 mesh elements, $2-4 \mathrm{~h}$ was required on a $2.6 \mathrm{GHz} / 512 \mathrm{MB}$ Pentium 4 . A refined mesh was used near the working electrode boundary while the mesh becomes coarser towards the free electrolyte region. Typically, 7-14 iterations were needed to meet the convergence criterion. The number of mesh elements was approximately 12,413 for the secondary current distribution. For the tertiary current distribution, the number of mesh elements varied depending on the diffusion layer thickness. There were 98,172 mesh elements for a $100 \mu \mathrm{m}$ thickness and 231,612 mesh elements for a $20 \mu \mathrm{m}$ diffusion layer thickness.

Computation was started using a constant applied current density for the counter electrode. Constant initial values for the potential distribution in the solution and concentration along the cathode are assumed. The computation was solved by a successive substitution procedure. The surface overpotential at a given iteration was damped with the previous value until convergence to within $1 \mathrm{mV}$ was achieved. The iteration proceeded until convergence when an agreement on the working electrode 


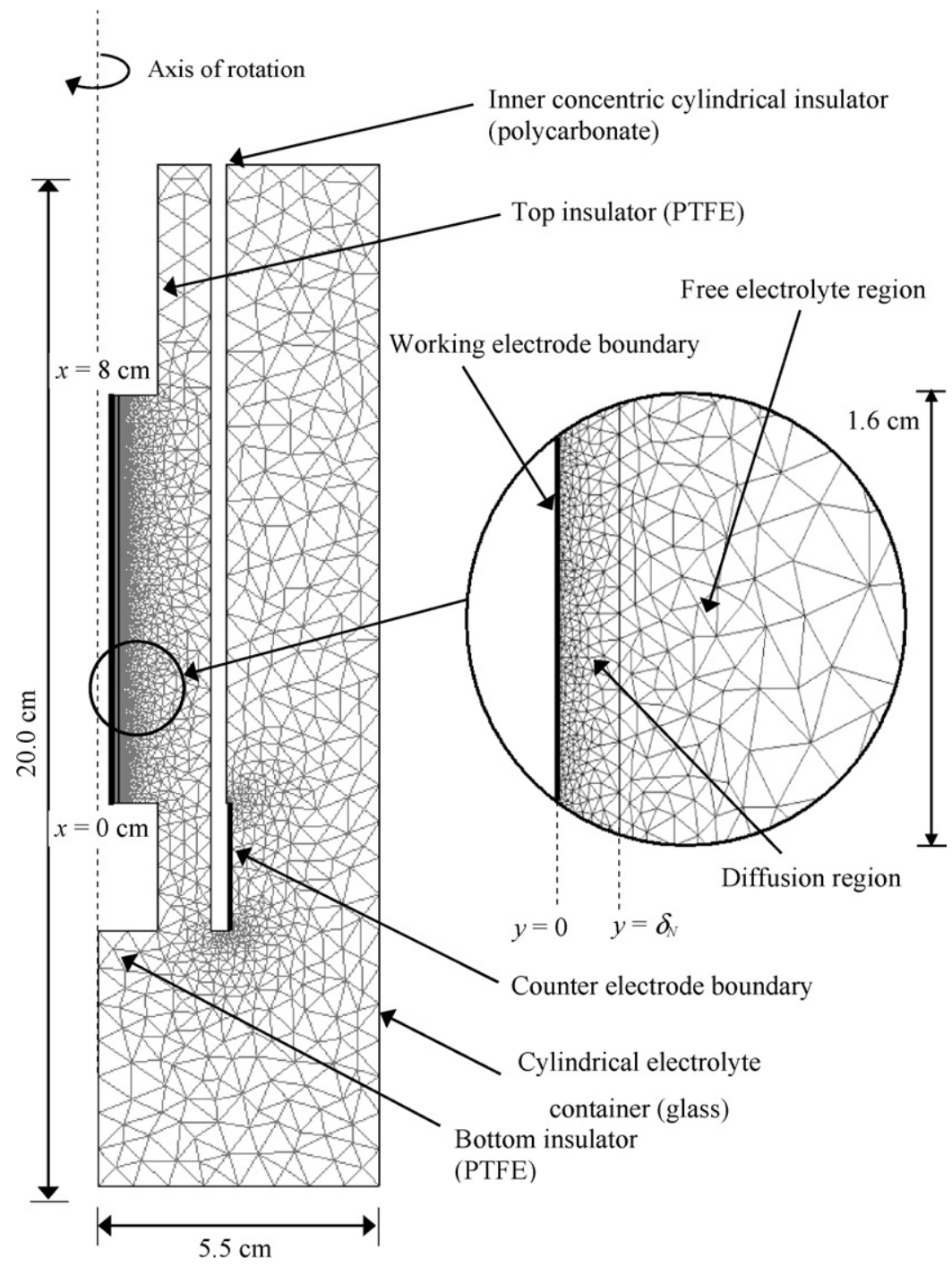

Fig. 2. Generation of 2D triangular meshes for the shaded area in Fig. 1. The enlarged circle shows the meshes generated inside the diffusion layer region and free electrolyte region. The bold lines indicate the electrode surfaces, all other surfaces are insulators.

Table 1

Parameters used in the numerical simulation

\begin{tabular}{ll}
\hline Working electrode characteristics & \\
RCE diameter, $d(\mathrm{~cm})$ & 0.6 \\
RCE length, $h(\mathrm{~cm})$ & 8.0 \\
Electrolyte properties & 0.35 \\
$\quad$ Electrolytic conductivity, $\kappa\left(\Omega^{-1} \mathrm{~cm}^{-1}\right)$ & $5.0 \times 10^{-5}$ \\
Bulk concentration of cupric ions, $c_{\mathrm{b}}\left(\mathrm{mol} \mathrm{cm}^{-3}\right)$ & $4.2 \times 10^{-6}$ \\
Diffusion coefficient of cupric ions, $D\left(\mathrm{~cm}^{2} \mathrm{~s}^{-1}\right)$ & $1.09 \times 10^{-2}$ \\
Kinematic viscosity, $v\left(\mathrm{~cm}^{2} \mathrm{~s}^{-1}\right)$ & \\
Kinetic parameters for copper deposition & 0.0525 \\
Tafel slope, $b_{\mathrm{c}}(\mathrm{V})$ & $-5.37 \times 10^{-5}$ \\
Exchange current density, $j_{\mathrm{o}}\left(\mathrm{A} \mathrm{cm}{ }^{-2}\right)$ & \\
\hline
\end{tabular}

Kinetic parameters were obtained from experimental measurements on copper electrodeposition from $50 \mathrm{mM} \mathrm{CuSO}_{4}$ and $0.5 \mathrm{M} \mathrm{Na}_{2} \mathrm{SO}_{4}$ at $\mathrm{pH} 2$ and $20^{\circ} \mathrm{C}$. The working-, counter- and reference electrodes were 316 stainless steel, $\mathrm{Pt} / \mathrm{Ti}$ and $\mathrm{Ag} / \mathrm{AgCl}$, respectively. was obtained for the local current density, overpotential and surface concentration.

The parameters used for the numerical simulation are listed in Table 1 . The values of $b_{\mathrm{c}}$ and $j_{\mathrm{o}}$ were obtained from experimental measurements. The test system was copper electrodeposition from an acid sulfate electrolyte containing $50 \mathrm{mM} \mathrm{Cu}_{2} \mathrm{SO}_{4}$ and $0.5 \mathrm{M} \mathrm{Na}_{2} \mathrm{SO}_{4}$ at $\mathrm{pH} 2$ and $20^{\circ} \mathrm{C}$. Table 2 shows examples of the average current density used in the investigations, including

Table 2

Examples of average current density used in the investigations

\begin{tabular}{lc}
\hline$j_{\text {ave }}\left(\mathrm{A} \mathrm{cm}^{-2}\right)$ & $W a_{\mathrm{T}}$ \\
\hline 0.01 & 229.7 \\
0.05 & 45.9 \\
1 & 2.30 \\
5 & 0.46 \\
10 & 0.23 \\
15 & 0.15 \\
20 & 0.11 \\
\hline
\end{tabular}

$W a_{\mathrm{T}}$ is the Wagner number defined according to the Tafel approximation. 
Table 3

Estimated Nernst diffusion layer thickness, $\delta_{\mathrm{N}}$, mass transport coefficient, $k_{\mathrm{m}}$, and limiting current density, $j_{\mathrm{L}}$ for various electrode rotation speeds

\begin{tabular}{|c|c|c|c|c|c|c|}
\hline$\omega(\mathrm{rpm})$ & $U\left(\mathrm{~cm} \mathrm{~s}^{-1}\right)$ & $\delta_{\mathrm{N}}(\mu \mathrm{m})$ & $k_{\mathrm{m}}\left(10^{-3} \mathrm{~cm} \mathrm{~s}^{-1}\right)$ & \multicolumn{3}{|l|}{$j_{\mathrm{L}}\left(\mathrm{mAcm}^{-2}\right)$} \\
\hline 132 & 4.15 & 100 & 0.42 & 3.92 & 4.10 & 4.3 \\
\hline 351 & 11.03 & 50 & 0.84 & 7.78 & 8.12 & 4.2 \\
\hline 480 & 15.08 & 40 & 1.05 & 9.68 & 10.09 & 4.0 \\
\hline 750 & 23.57 & 30 & 1.40 & 13.24 & 13.57 & 2.5 \\
\hline
\end{tabular}

Limiting current density values are (a) calculated directly from Eq. (19) and the Nernst diffusion layer theory and (b) calculated from the numerical simulation using the finite element technique via FEMLAB ${ }^{\mathrm{TM}}$. The percentage error is $((a)-(b)) /(a) \times 100$.

the calculated Wagner number defined according to the Tafel approximation [19]:

$W a_{\mathrm{T}}=\frac{b_{\mathrm{c}} \kappa}{j_{\mathrm{ave}} L}$

where $L$ is a characteristic length (equal to the length of the RCE). The Wagner number is used to characterise the relative importance of charge transfer control on the current distribution. The current distribution is expected to become more uniform as the Wagner number increases. Table 3 shows the estimated Nernst diffusion layer thickness calculated using Eq. (11).

\section{Results and discussion}

Fig. 3 shows the simulated primary current distribution along the working electrode. An analytical Eq. (1) for a similar RCH cell is also shown $[9,10]$. The simulated primary current distribution was fitted by an exponential decay function and the linear

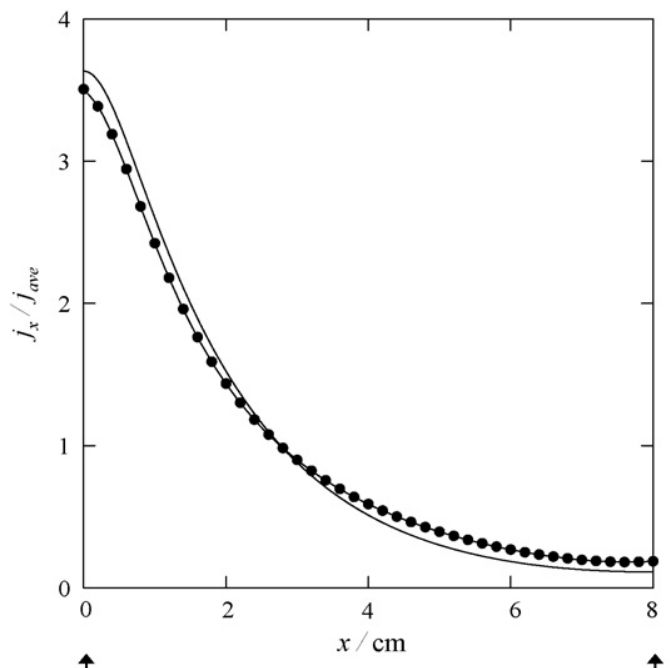

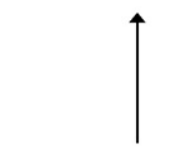

Highest current density (Closer to the counter electrode)

Fig. 3. Primary current distribution calculated from (-) FEMLAB ${ }^{\mathrm{TM}}$ via finite element analysis and $(\bullet)$ Landolt and co-workers $[9,10]$ via a theoretical analysis of Laplace equation.

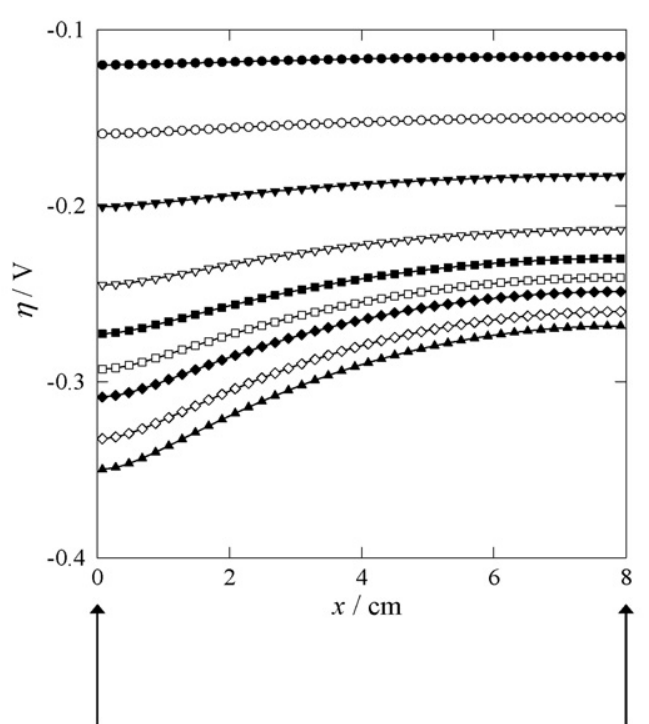

Highest current density

$\begin{array}{cc}\text { Highest current density } & \text { Lowest current density } \\ \text { (a) (Closer to the counter electrode) } & \text { (Furthest from the counter electrode) }\end{array}$

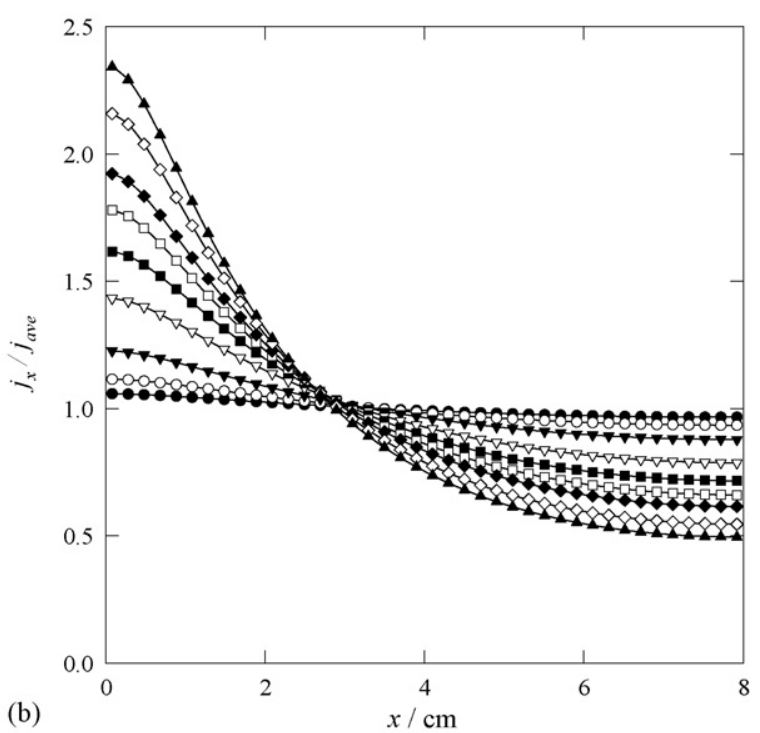

Fig. 4. Simulation for the secondary current distribution. (a) Overpotential vs. distance profile. (b) Dimensionless current density vs. distance profile. The design demonstrates the non-uniform current and potential distribution occurred along the length of the cathode. (O) $0.5 \mathrm{~mA} \mathrm{~cm}^{-2}$; (○) $1 \mathrm{~mA} \mathrm{~cm}^{-2}$;

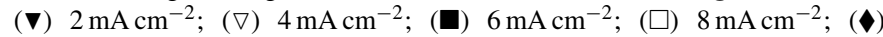
$10 \mathrm{~mA} \mathrm{~cm}^{-2} ;(\diamond) 14 \mathrm{~mA} \mathrm{~cm}^{-2} ;(\boldsymbol{\Delta}) 18 \mathrm{~mA} \mathrm{~cm}^{-2}$. 
regression coefficient was approximately 0.995 :

$$
\frac{j_{x}}{j_{\text {ave }}}=4.07 \exp \left[-3.96\left(\frac{x}{h}\right)\right]
$$

The simulated primary current distribution is dependent on the geometry of the $\mathrm{RCH}$ cell and follows a non-uniform profile along the cathode. The dimensionless current density decreased monotonically with the distance away from the counter electrode. However, the simulated curve did not coincide exactly with Eq. (1). This was because the cell dimensions of the $\mathrm{RCH}$ cell were not exactly identical to the one used for Eq. (1) $[9,10]$. However, the cells showed similarity in the cell geometrical ratio such as the ratio of the working electrode length to the distance between the inner insulator wall and working electrode surface.

The simulated secondary current distribution is shown in Fig. 4(a and b). Fig. 4(a) shows the variation of overpotential and (b) shows the dimensionless current density for a range of applied currents. The position $x=0$ is nearest to the counter electrode and $x=8$ is furthest from the counter electrode. The results clearly demonstrated that the design of the $\mathrm{RCH}$ cell
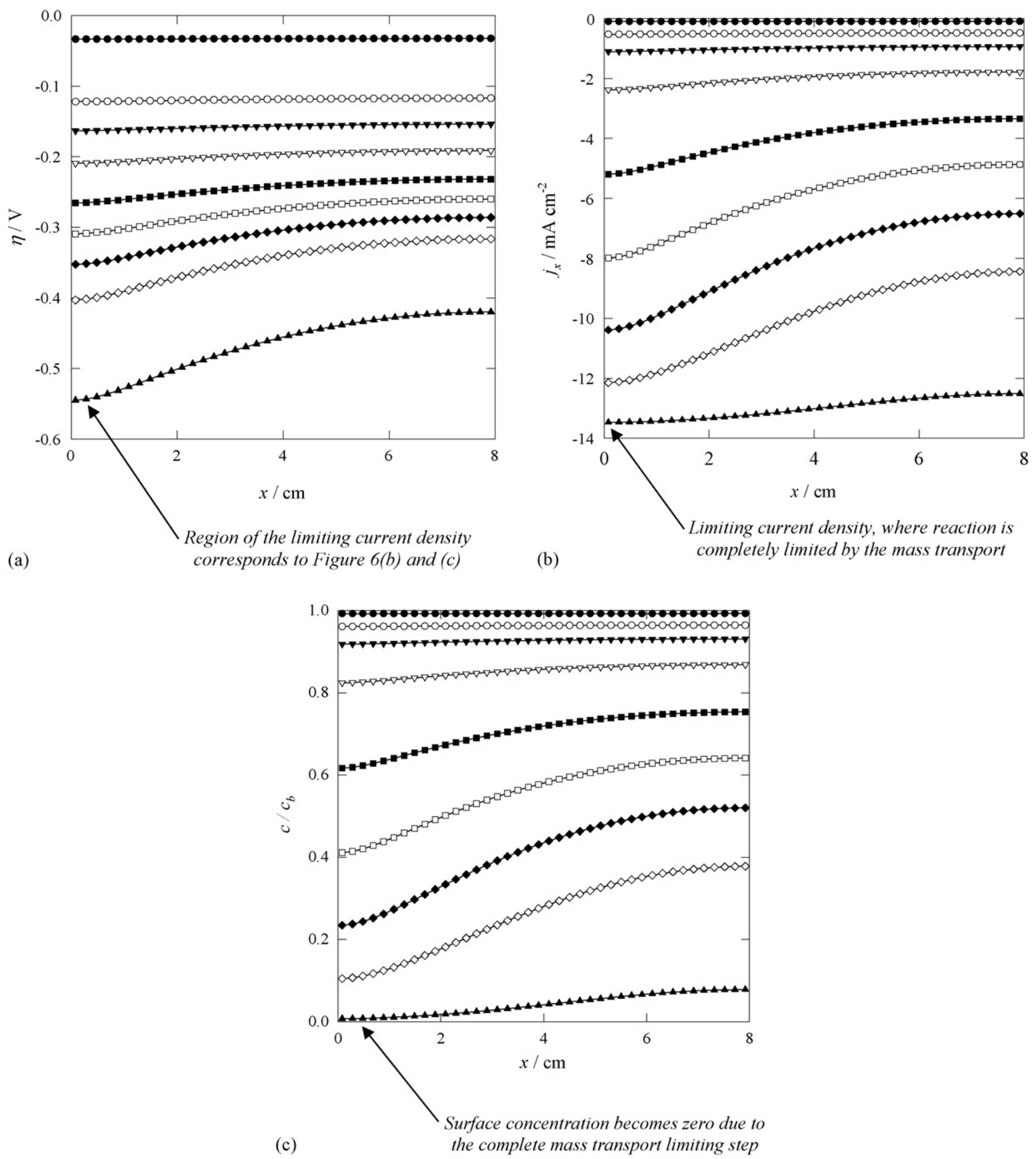

Fig. 5. Simulation for the tertiary current distribution. Mass transport and charge transfer are used in the simulation. Electrode rotation speed is $750 \mathrm{rpm}$ with an estimated $30 \mu \mathrm{m}$ diffusion layer thickness. (a) Overpotential vs. distance profile. (b) Dimensionless current density vs. distance profile. The concentration profile

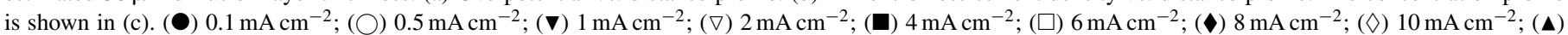
$13 \mathrm{~mA} \mathrm{~cm}^{-2}$. 
gave a continuous variation in local current density along the length of the cathode. By comparing Fig. 3 and Fig. 4(b), it is clear that the primary current distribution model was not sufficient to describe the phenomena of copper electrodeposition under non-equilibrium condition. This was because the primary current distribution model did not include the charge transfer effect. It was therefore expected that the calculated secondary current distribution will be more representative of the practical current distribution which would occur for this system.

Although the simulated results clearly showed the importance of including the effect of charge transfer the validity of the secondary current distribution model can only be used for certain overpotential range. This was because as the applied current density increased or overpotential departed significantly from the equilibrium potential, the surface concentration of copper ions deviated significantly from its bulk concentration. For example, if the local current density were $20 \%$ of the limiting current density, then the surface concentration would be reduced to around $80 \%$ of its bulk concentration. At higher current density, charge transfer alone cannot describe the reduction reaction of copper ions on the RCH cell. The secondary current distribution simulations will be valid when the average current density is much less than the limiting current density.

The distribution of overpotential, current density and concentration along the cathode surface, determined from the tertiary current distribution model are shown in Fig. 5(a-c). The cathode rotation speed was $750 \mathrm{rpm}$ with an estimated $30 \mu \mathrm{m}$ Nernst diffusion layer thickness. The figures demonstrate the transition from charge transfer control, through mixed (charge transfer and mass transport) control to complete mass transport control as the rate-controlling factor. The shape of the overpotential distribution (Fig. 5(a)) is similar to that obtained for the secondary current distribution (Fig. 4(a)), although a higher overpotential was found at high applied current densities. In Fig. 5(b), as the applied current densities increased, the limiting current density $\left(13.24 \mathrm{~mA} \mathrm{~cm}^{-2}\right)$ approached at the end of the electrode leading to much higher overpotential in this region. To check that conservation of charge was preserved, the average current on the working electrode was found to be exactly equal to the total current on the counter electrode, which shows that the boundary conditions used throughout the simulations was adequately described. Fig. 5(c) showed that the surface concentration was significantly lower than the bulk concentration, even for moderate current densities. This lead to an increased overpotential along the length of the cathode. For applied current density at $13 \mathrm{~mA} \mathrm{~cm}^{-2}$, the surface concentration almost approached zero at the end of the electrode $(x=0)$, consistent with the observation of limiting current conditions in this region (Fig. 5(b)).

Fig. 6 shows the calculated concentration profile inside the Nernst diffusion layer at a number of different positions along the electrode. The electrode rotation speed was $1300 \mathrm{rpm}$ with an estimated concentration boundary layer thickness of $20 \mu \mathrm{m}$ and $10 \mathrm{~mA} \mathrm{~cm}^{-2}$ applied current density. This figure demonstrates the capability of the $\mathrm{RCH}$ cell in obtaining a wide range of surface concentrations. In this case, almost $40 \%$ of surface

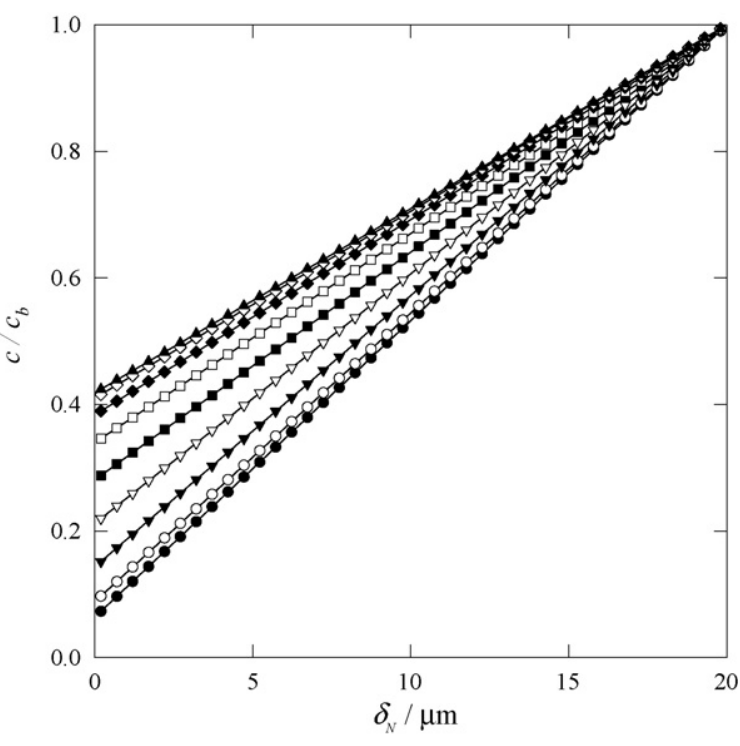

Fig. 6. Concentration profiles inside the Nernst diffusion layer. Electrode rotation speed is $1300 \mathrm{rpm}$ with an estimated $20 \mu \mathrm{m}$ diffusion layer thickness and applied current density is $10 \mathrm{~mA} \mathrm{~cm}^{-2}$. The position $x=0$ is nearest to the counter electrode and $x=8$ is furthest from the counter electrode. $(\bigcirc) 0 \mathrm{~cm} ;(\bigcirc) 1 \mathrm{~cm}$;

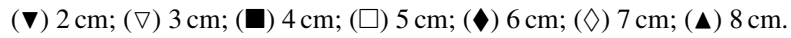

concentration was obtainable over a single electrode. The current and potential relationship varied non-uniformly along the height of the cathode. As expected the concentration varied linearly and this occurred at $0<c / c_{\mathrm{b}}<1$, which is the mixed (charge transfer and mass transport) control region.

Fig. 7 shows the variation of local current density as a function of local overpotential calculated along the cathode of the $\mathrm{RCH}$ cell. The curves were obtained by plotting the current density at each location on the electrode against the overpotential at that location, at each electrode rotation speed. The simulated voltammetry clearly shows the charge transfer, mixed (charge

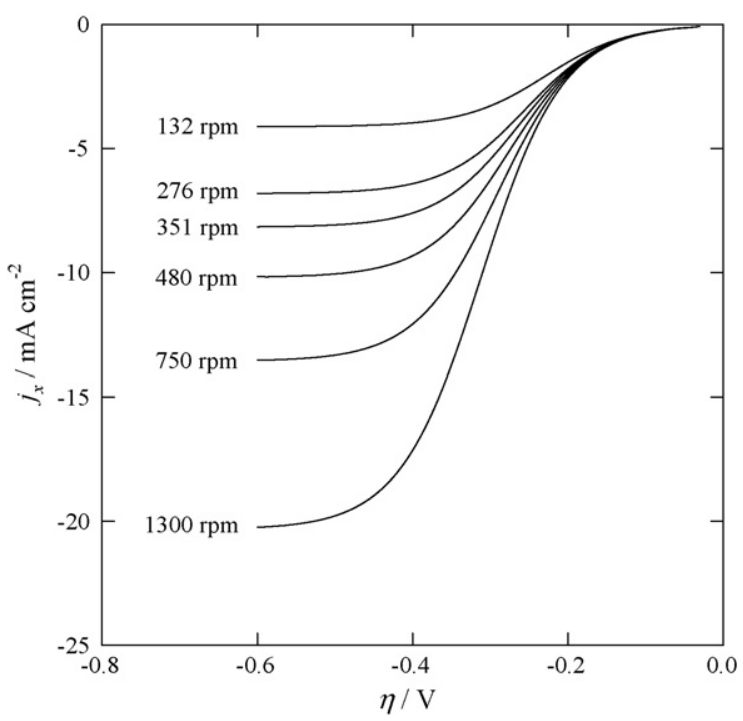

Fig. 7. Local current density as a function of local overpotential at various locations $(0 \mathrm{~cm}<x<8 \mathrm{~cm})$ along the $\mathrm{RCH}$ working electrode, for a range of rotation speeds $(132-1300 \mathrm{rpm})$ 


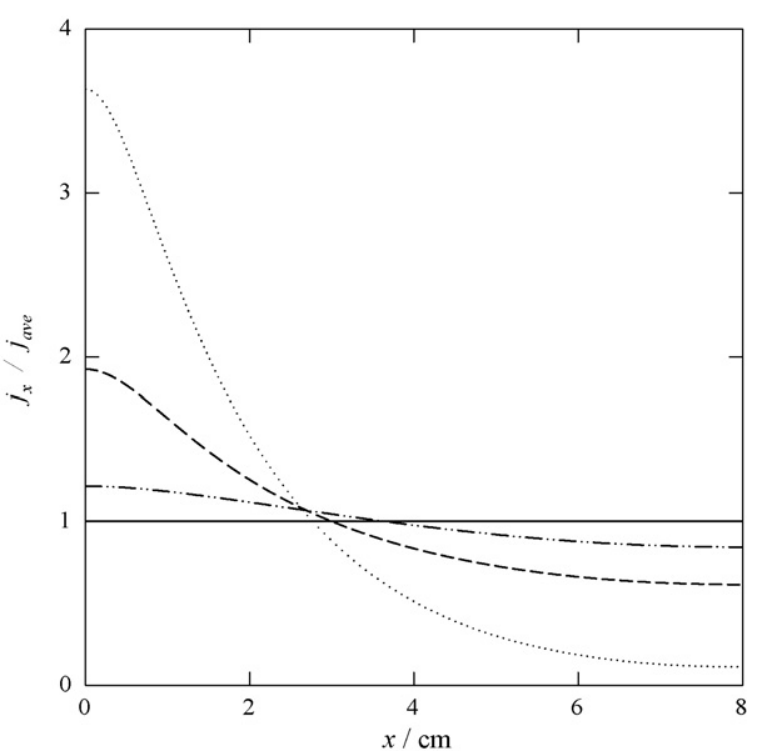

Fig. 8. Dimensionless current density vs. distance profiles. (-) Uniform current distribution; $(\cdots)$ primary current distribution; (- - -) secondary current distribution; (- - - ) tertiary current distribution. Average current density is $10 \mathrm{~mA} \mathrm{~cm}^{-2}$ and working electrode rotation speed is $750 \mathrm{rpm}$.

transfer and mass transport) and mass transport control region. Table 3 shows a comparison between the limiting current densities calculated by two different methods. The simulated limiting current densities were close to the results calculated from the dimensionless mass transport correlation $[17,18]$ :

$S h=0.079 R e^{0.70} S c^{0.356}$

where $S h$ is the Sherwood number describing the mass transport due to forced convection, $R e$ the Reynolds number describing the fluid flow and $S c$ is the Schmidt number describing the electrolyte transport properties. The dimensionless groups in Eq. (18) may be expanded to give:

$\left(\frac{j_{\mathrm{L}} d}{z F c_{\mathrm{b}} D}\right)=0.079\left(\frac{U d}{v}\right)^{0.70}\left(\frac{v}{D}\right)^{0.356}$

The limiting current density can be expressed as:

$j_{\mathrm{L}}=0.079 z F_{\mathrm{b}} d^{-0.3} U^{0.70} v^{-0.344} D^{0.644}$

The difference between the simulated current densities and the values calculated using Eq. (20) is between $2.5 \%$ and $4.3 \%$ for the range of electrode rotation speeds studied, and in all cases, the simulated current densities were higher than expected. The systematic error is a consequence of the numerical approach taken but a detailed analysis has not been carried out since the size of the discrepancy is relatively small. The agreement is well within the accuracy of the generalised dimensionless mass transport correlation used over a wide range of flow conditions.

A comparison of all three types of current distribution is shown in Fig. 8. The least uniform dimensionless current density against distance profile was the primary current distribution, followed by secondary current distribution and tertiary current distribution was the most uniformly distributed profile. It was clear that the tertiary current distribution was the most appropri- ate simulation to use when the effect of concentration gradient cannot be neglected. Demonstrated by these simulations, a variety of reactions on the $\mathrm{RCH}$ cell can be modelled, for example alloy deposition and high-speed electroplating. It can be particularly useful to simulate the mass transport effect under turbulent flow conditions. The deliberately non-uniform distribution profile is advantageous because it allows more points to be achieved in a single experiment/simulation.

\section{Summary}

The primary, secondary and tertiary current distributions along the cathode of the rotating cylinder Hull cell have been calculated under turbulent flow conditions using commercially available finite element software. Three regimes of operation were observed. At low applied currents, kinetic limited conditions prevail and hence a relatively uniform current density distribution was obtained. As the applied current was increased, the effect of the potential distribution due to ohmic effects became more significant and large variations in the local current density along the electrode were observed. At high currents, the electrode approached mass transport limiting conditions and a uniform current distribution was obtained. Simulations demonstrated that a wide range of concentration, local current density and overpotential was achievable in the rotating cylinder Hull cell.

\section{Acknowledgements}

The authors are grateful to Dr. Keith Dawes of Windsor Scientific, Slough, United Kingdom for discussions and provision of equipment. Dr Carlos Ponce de León provided assistance with the figures.

\section{Appendix A. Nomenclature}

$b_{\mathrm{c}} \quad$ Tafel slope for the cathodic reaction (V)

$c$ concentration at the electrode surface $\left(\mathrm{mol} \mathrm{cm}^{-3}\right)$

$c_{\mathrm{b}} \quad$ bulk concentration of electroactive species $\left(\mathrm{Cu}^{2+}\right)$ $\left(\mathrm{mol} \mathrm{cm}{ }^{-3}\right)$

$d \quad$ diameter of rotating cylinder electrode $(\mathrm{cm})$

$D \quad$ diffusion coefficient of electroactive species $\left(\mathrm{Cu}^{2+}\right)$ $\left(\mathrm{cm}^{2} \mathrm{~s}^{-1}\right)$

$F \quad$ Faraday constant $\left(96,485 \mathrm{C} \mathrm{mol}^{-1}\right)$

$h \quad$ length of the RCE working electrode (A)

$j \quad$ current density $\left(\mathrm{A} \mathrm{cm}^{-2}\right)$

$j_{\text {ave }} \quad$ average current density $\left(\mathrm{A} \mathrm{cm}^{-2}\right)$

$j_{\mathrm{L}} \quad$ limiting current density $\left(\mathrm{A} \mathrm{cm}^{-2}\right)$

$j_{\mathrm{o}} \quad$ exchange current density $\left(\mathrm{A} \mathrm{cm}^{-2}\right)$

$j_{x} \quad$ local current density along the $\mathrm{RCH}$ cathode $\left(\mathrm{A} \mathrm{cm}^{-2}\right)$

$k_{\mathrm{m}} \quad$ mass transport coefficient $\left(\mathrm{cm} \mathrm{s}^{-1}\right)$

Re Reynolds number, $R e=U d / v$

$S c \quad$ Schmidt number, $S c=v / D$

Sh Sherwood number, $S h=j_{\mathrm{L}} d / z F c_{\mathrm{b}} D$

$U \quad$ peripheral velocity of rotating cylinder electrode $\left(\mathrm{cm} \mathrm{s}^{-1}\right)$ 
Wa $\quad$ Wagner number (defined according to Tafel approximation)

$x$ distance along the rotating cylinder cathode $(\mathrm{cm})$

$z \quad$ number of electrons in the electrode process

\section{Greek letters}

$\delta_{\mathrm{N}} \quad$ Nernst diffusion layer thickness $(\mathrm{cm})$

$\phi \quad$ potential in the electrolyte (V)

$\phi_{0} \quad$ potential of the solution adjacent to the working electrode $(\mathrm{V})$

$\eta \quad$ overpotential (V)

$\kappa \quad$ electrolytic conductivity $\left(\Omega^{-1} \mathrm{~cm}^{-1}\right)$

$v \quad$ kinematic viscosity of electrolyte $\left(\mathrm{cm}^{2} \mathrm{~s}^{-1}\right)$

$\omega \quad \mathrm{RCE}$ rotation speed (rpm)

\section{References}

[1] R.O. Hull, Proc. Am. Electroplat. Soc. 27 (1939) 52.

[2] A.K. Graham, H.L. Pinkerton, Proc. Am. Electroplat. Soc. 50 (1961) 43.

[3] D.R. Gabe, G.D. Wilcox, J. Gonzalez-Garcia, F.C. Walsh, J. Appl. Electrochem. 28 (1998) 759.

[4] C.T.J. Low, C. Ponce de Leon, F.C. Walsh, Aust. J. Chem. 58 (2005) 246.

[5] A.F.S. Afshar, D.R. Gabe, B. Sewell, Trans. Inst. Met. Finish. 69 (1) (1991) 37.
[6] I. Kadija, J.A. Abys, V. Chinchankar, H.K. Straschil, Plat. Surf. Finish. 78 (10) (1991) 62.

[7] C. Madore, D. Landolt, Plat. Surf. Finish. 80 (11) (1993) 73

[8] C. Madore, D. Landolt, C. Hasenpflug, J.A. Hermann, Plat. Surf. Finish. (August) (1995) 36.

[9] C. Madore, M. Matlosz, D. Landolt, J. Appl. Electrochem. 22 (12) (1992) 1155.

[10] C. Madore, A.C. West, M. Matlosz, D. Landolt, Electrochim. Acta 37 (1) (1992) 69.

[11] Ph. Mandin, C. Fabian, D. Lincot, Electrochim. Acta 51 (2006) 4067.

[12] RotaHull ${ }^{\circledR}$, The Hull Cell with the Rotating Cylinder Electrode, Windsor Scientific Ltd., Slough, United Kingdom, 2001.

[13] D. Pletcher, A First Course in Electrode Processes, The Electrochemical Consultancy, Romsey, 1991.

[14] F.C. Walsh, A First Course in Electrochemical Engineering, The Electrochemical Consultancy, Romsey, 1993.

[15] J.S. Newman, Electrochemical Systems, Prentice-Hall, Englewood Cliffs, NJ, 1973.

[16] C.M.A. Brett, A.M.O. Brett, Electrochemistry: Principles, Methods, and Applications, Oxford University Press Inc., New York, 1993.

[17] M. Eisenberg, C.W. Tobias, C.R. Wilke, Chem. Eng. Prog. Symp. Ser. 51 (1955) 1.

[18] M. Eisenberg, C.W. Tobias, C.R. Wilke, J. Electrochem. Soc. 101 (6) (1954) 306.

[19] M. Matlosz, C. Creton, C. Clerc, D. Landolt, J. Electrochem. Soc. 134 (12) (1987) 3015 